\title{
Ventilation-Perfusion Lung Scanning: Stuck in a Rut?
}

$\mathbf{T}$ he methodology for high-quality ventilation-perfusion (V/Q) imaging is available at almost all nuclear medicine sites in the United States and throughout the world. However, a large number of the sites continue to use older techniques, originally introduced over 40 y ago. This results in lower-accuracy imaging for pulmonary embolism, when more modern approaches can achieve accuracy equal to or greater than $\mathrm{CT}$ angiography, which has become the de facto standard in recent years.

Perfusion lung scanning has been done with $99 \mathrm{~m}$ Tcmacroaggregated albumin since 1964 (1). This agent has been successful, and although albumin microspheres have also been used, the quality of the imaging of lung perfusion is limited by instrumentation and not by the radiopharmaceutical.

Ventilation imaging was initially done with ${ }^{133} \mathrm{Xe}$, beginning in 1969 (2), although at that time radioaerosols were also beginning to be studied. Since then, several different approaches to ventilation imaging have been studied, including ${ }^{81 \mathrm{~m}} \mathrm{Kr}$, aerosols with different radiopharmaceuticals, and more recently Technegas (Cyclomedica Ltd.). ${ }^{133} \mathrm{Xe}$ ventilation imaging is generally less effective than radioaerosols in evaluations for pulmonary embolism because of greater technical complexity, limited views without SPECT capability, problems with patient tolerance, and difficulty in studying patients on ventilators.

The radiopharmaceutical used in the initial radioaerosol studies was human serum albumin or derivatives of albumin. Several other tracers were investigated, including diethylenetriaminepentaacetic acid (DTPA), pyrophosphate, and various colloids. Interestingly, although the conclusions in these papers were that pyrophosphate and colloid resulted in higher-quality studies (3), it was DTPA that was widely adopted. This was probably because the nebulizer manufacturers used it in their clinical trials and it was suggested in the package insert. The major disadvantage of DTPA is rapid washout, which can occur in patients with inflammatory lung disease.

In the mid 1980s, investigators began to look at the feasibility of SPECT imaging for V/Q studies (4). Perfusion

Received Jun. 26, 2014; revision accepted Jun. 30, 2014.

For correspondence or reprints contact: Michael M. Graham, University of lowa, 3863 JPP Department of Radiology, 200 Hawkins Dr., lowa City, IA 52242.

E-mail: michael-graham@uiowa.edu

Published online Jul. 17, 2014.

COPYRIGHT (C) 2014 by the Society of Nuclear Medicine and Molecular Imaging, Inc.

DOI: 10.2967/jnumed.114.144949 studies were done with ${ }^{99 \mathrm{~m}} \mathrm{Tc}$-macroaggregated albumin, and ventilation studies were done with $99 \mathrm{mTc}$-human serum albumin. The results were tantalizing but did not have a comparison with a gold standard, and these initial studies had little impact on practice. This began to change in the early 2000s. Several papers were published suggesting that V/Q imaging should be done using SPECT (5-7). More recently, Gutte et al. (8) convincingly demonstrated that V/Q SPECT was more accurate than CT angiography in a head-to-head study in which CT angiography was done immediately after V/Q SPECT using the same system, a Symbia SPECT/CT scanner (Siemens). The agents used were ${ }^{99 \mathrm{~m} T c-m a c r o a g-}$ gregated albumin and ${ }^{81 \mathrm{~m}} \mathrm{Kr}$. Similar results have been reported using ${ }^{99 \mathrm{~m}} \mathrm{Tc}$-macroaggregated albumin and Technegas (9). Although neither ${ }^{81 \mathrm{~m}} \mathrm{Kr}$ nor Technegas is available in the United States, it is feasible to do ventilation SPECT imaging with ${ }^{99 m}$ Tc-DTPA (10) and with ${ }^{99 m}$ Tc-sulfur colloid (11).

This editorial is not intended to be a comprehensive review of SPECT lung scanning. Rather, it is intended as a wake-up call for nuclear medicine sites to carefully look at their practice and seriously consider changing from V/Q planar imaging to SPECT. At the University of Iowa we have been doing ventilation imaging with ${ }^{99 \mathrm{~m}} \mathrm{Tc}$-sulfur colloid since 2000 . We started doing V/Q imaging with SPECT 2 y ago, and our results appear to reflect the reports in the literature. The overall time for the study is about the same as for planar imaging, and there is less need to constantly reposition the camera during the study. In addition, the approach has been well accepted by the technologists.

It is now clear that V/Q SPECT is the better way to image for pulmonary embolism. V/Q SPECT is recommended as the standard of care by the European Association of Nuclear Medicine, but adoption of V/Q SPECT has been slow in the United States. The reticence seems to have stemmed from confusion about the approach to interpretation of the studies. This issue appears to have been solved, and there are solid recommendations in the European literature (12) that eliminate the probability categories and in essence use a binary reading for presence or absence of pulmonary embolism. In our practice, V/Q SPECT has significantly reduced the number of indeterminate studies and also increased confidence among readers.

It is now time to move past the PIOPED approach for V/Q imaging and adopt the most modern methodology. 


\section{REFERENCES}

1. Taplin GV, Johnson DE, Dore EK, Kaplan HS. Lung photoscans with macroaggregates of human serum radioalbumin: experimental basis and initial clinical trials. Health Phys. 1964;10:1219-1227.

2. Loken MK, Medina JR, Lillehei JP, L'Heureux P, Kush GS, Ebert RV. Regional pulmonary function evaluation using xenon 133, a scintillation camera, and computer. Radiology. 1969;93:1261-1266.

3. Peltier P, Chatal JF. ${ }^{99 \mathrm{~m}}$ Tc-DTPA and ${ }^{99 \mathrm{~m}}$ Tc-rhenium sulfur aerosol compared as adjuncts to perfusion scintigraphy in patients with suspected pulmonary embolism. Eur J Nucl Med. 1986;12:254-257.

4. Touya JJ, Corbus HF, Savala KM, Habibe MN. SPECT in the diagnosis of pulmonary thromboembolism. Semin Nucl Med. 1986;16:306-336.

5. Meignan MA. Lung ventilation/perfusion SPECT: the right technique for hard times. J Nucl Med. 2002;43:648-651.

6. Collart JP, Roelants V, Vanpee D, et al. Is a lung perfusion scan obtained by using single photon emission computed tomography able to improve the radionuclide diagnosis of pulmonary embolism? Nucl Med Commun. 2002;23:1107-1113.

7. Reinartz P, Wildberger JE, Schaefer W, Nowak B, Mahnken AH, Buell U. Tomographic imaging in the diagnosis of pulmonary embolism: a comparison between V/Q lung scintigraphy in SPECT technique and multislice spiral CT. J Nucl Med. 2004;45:1501-1508.

8. Gutte H, Mortensen J, Jensen CV, et al. Detection of pulmonary embolism with combined ventilation-perfusion SPECT and low-dose CT: head-to-head comparison with multidetector CT angiography. J Nucl Med. 2009;50:19871992.

9. Quirce R, Ibáñez-Bravo S, Jiménez-Bonilla J, et al. Contribution of V/Q SPECT to planar scintigraphy in the diagnosis of pulmonary embolism. Rev Esp Med Nucl Imagen Mol. 2014;33:153-158.

10. Lu Y, Lorenzoni A, Fox JJ, et al. Non-contrast perfusion SPECT/CT: a new test for the expedited, high accuracy diagnosis of acute pulmonary embolism. Chest. January 2, 2014 [Epub ahead of print].

11. Ponto JA, Graham MM, Bricker JA. Alternatives to technetium 99m pentetate for radioaerosol inhalation lung imaging. J Am Pharm Assoc (Wash). 2002; 42:112-114.

12. Bajc M, Neilly JB, Miniati M, Schuemichen C, Meignan M, Jonson B. EANM guidelines for ventilation-perfusion scintigraphy: Part 2. Algorithms and clinical considerations for diagnosis of pulmonary emboli with V/P(SPECT) and MDCT. Eur J Nucl Med Mol Imaging. 2009;36:15281538 . 